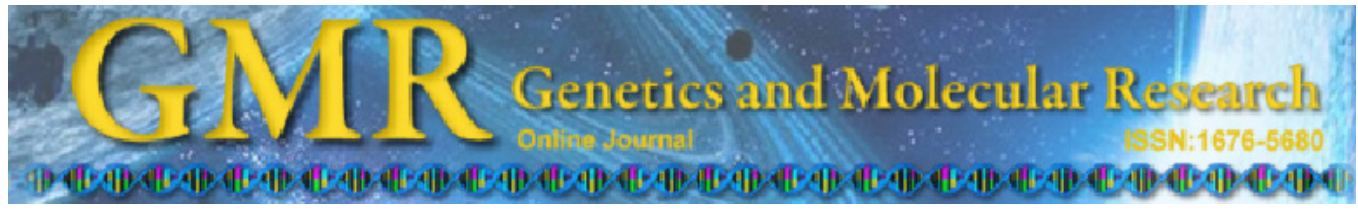

Case Report

\title{
3p partial trisomy and 13q partial monosomy with congenital malformations and psychomotor developmental delay
}

\author{
M.J. Rodovalho-Doriqui ${ }^{1}$, P.L. Freitas ${ }^{1}$, J.D. Pinho ${ }^{1}$, L.R. Cavalli ${ }^{2}$ and \\ S.R.F. Pereira ${ }^{1}$ \\ ${ }^{1}$ Laboratório de Genética e Biologia Molecular, Departamento de Biologia, \\ Universidade Federal do Maranhão, São Luís, MA, Brasil \\ ${ }^{2}$ Georgetown University Medical Center, Washington, DC, USA
}

Corresponding author: S.R.F. Pereira

E-mail: silmaregina@yahoo.com.br

Genet. Mol. Res. 12 (3): 2562-2566 (2013)

Received November 9, 2012

Accepted March 15, 2013

Published July 24, 2013

DOI http://dx.doi.org/10.4238/2013.July.24.7

\begin{abstract}
We examined a girl presenting neuropsychomotor developmental delay and multiple malformations including antenatal and postnatal growth retardation, congenital heart defect, and facial dysmorphisms. Cytogenetic analysis was performed on peripheral blood lymphocytes with the GTG-banding technique, which revealed an unbalanced translocation: $46, \mathrm{XX}$, der(13)(13pter $\rightarrow 13 \mathrm{q} 34:: 3 \mathrm{p} 24 \rightarrow 3$ pter) pat. Karyotype analysis of the father demonstrated a balanced translocation, 46,XY,t $(3 ; 13)(\mathrm{p} 24 ; \mathrm{q} 34)$, indicating the inheritance of the derivative chromosome 13 . The mother karyotype was normal. We suggest that most of the structural malformations seen in this patient are due to the $3 p$ trisomy, while the neuropsychomotor alterations are a consequence of both chromosome aberrations.
\end{abstract}

Key words: Congenital malformations; Neuropsychomotor alterations; $3 p$ trisomy; $13 q$ monosomy 


\section{INTRODUCTION}

Partial trisomy $3 \mathrm{p}$ is a rare chromosomal abnormality, and it can be either de novo or inherited from one parent with a balanced translocation. It has been known as a syndrome with multiple congenital abnormalities and intellectual deficiency, including neuropsychomotor retardation. Clinical manifestations are quite varied, depending on the amount of $3 p$ material in the trisomic state. The partial 13q monosomy is a rare condition characterized by a wide range of clinical findings. Phenotype varies with the location and size of the deletion. It commonly produces malformations such as microcephaly, ear abnormalities, retrognathia, hypertelorism, palate fissures, hypotonia, and skeletal abnormalities, as well as psychomotor developmental delay and heart defects. We describe here a girl with both chromosomal alterations, and we suggest a correlation between each alteration and her phenotype.

\section{CASE REPORT}

We present a case report on a patient (LSS) of 19 months, who was the third child to a 23-year-old mother and a 45-year-old father, where the parents were unrelated. The mother had no familial history of congenital malformations or spontaneous miscarriage. The father had 20 other children and 3 of them had unknown causes of death.

The mother did not have any problems during the pregnancy, but she reported few fetal movements and amniotic fluid loss a few weeks before childbirth. She had a cesarean section, which was prolonged and dystocic due to the transverse position of the baby, who was cyanotic due to the intense suffering. Resuscitation was not necessary. The child had a 5-min Apgar score of 8 and normal newborn screening results. Birth weight was $3150 \mathrm{~g}$.

The child had psychomotor developmental delay (speech and motor), microcephaly, large forehead, hypertelorism, strabismus, small nose with anteverted nares, depressed nasal bridge, prominent short philtrum, large mouth with downturned corners, prominent posteriorly rotated low-set ears, retrognathia, widely spaced inverted nipples, short sternum, rightconvex thoracic scoliosis, and grade II systolic murmur (Figure 1). The patient was affected by dysphagia for any kind of food constitution, having a higher tolerance for liquids. Female genitalia was normal.
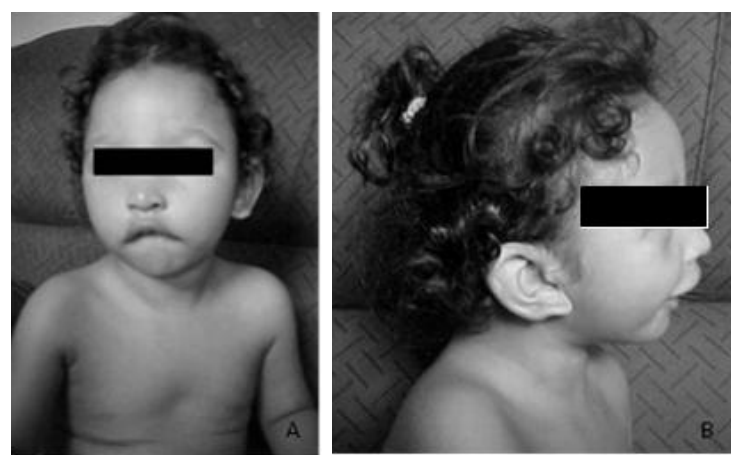

Figure 1. Clinical manifestations. A. Large forehead, small nose with anteverted nares, prominent short philtrum, large mouth with downturned angles, widely spaced nipples, and short sternum. B. Prominent low-set posteriorly rotated ears, retrognathia. 
The patient had an acyanotic congenital heart disease (large ostium secundum-type interatrial communication, with moderate hemodynamic repercussion) and also a discrete muscular hypotrophy. She was affected by repetition bronchopneumonia since the 26th day of life, leading to multiple hospital admissions. She died in the 19th month of life due to respiratory problems.

High-resolution cytogenetic analysis was performed in the patient and her parents, after culture of the lymphocytes from their peripheral blood according to previous studies (Ford and Hamerton, 1956; Yunis, 1976). We studied 50 metaphases by GTG banding treatment. The mother's karyotype was normal, while the father showed a balanced translocation (Figure $2)$, with a karyotype of $46, \mathrm{XY}, \mathrm{t}(3 ; 13)(\mathrm{p} 24 ; \mathrm{q} 34)$. The patient inherited the father's derivative chromosome 13, showing the karyotype 46,XX,der(13)(13pter $\rightarrow 13 \mathrm{q} 34:: 3 \mathrm{p} 24 \rightarrow 3$ pter)pat. The patient's parents signed an informed consent approved by the Ethics Committee of Universidade Federal do Maranhão allowing the publication of the clinical data and photographs.

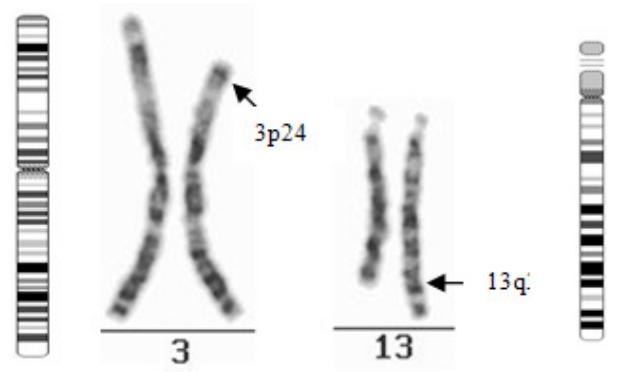

Figure 2. Father's 3 and 13 chromosomes at band level 550.

Most of the clinical manifestations described in our patient are known to occur in both trisomy $3 p$ and monosomy $13 q$ syndromes, individually. Other phenotype manifestations are compatible with the clinical alterations related to 3p trisomy patients (Reiss et al., 1986; Chen et al., 2008; Ginocchio et al., 2008; Tan et al., 2011; Han et al., 2012), and some are related to 13q monosomy (Schinzel, 1983; Brewer et al., 1998; Brooks et al., 2006; Ballarati et al., 2007; Quélin et al., 2009), as shown in Tables 1 and 2.

The partial 13q monosomy commonly produces malformations such as microcephaly, ear abnormalities, retrognathia, hypertelorism, palate fissures, hypotonia, and skeletal abnormalities, as well as psychomotor development delay and heart defects (Table 1). The partial $3 p$ trisomy has been known as a syndrome with multiple congenital abnormalities and intellectual deficiency, characterized by micrognathia, short neck, hypertelorism, large mouth with downturned angles, prominent philtrum, speech delay, congenital heart disease, and neuropsychomotor retardation. Most patients die during the first two years of life (Table 2). Clinical manifestations are quite varied, depending on the amount of $3 p$ material in the trisomic state.

In general, phenotypes associated with deletions are more severe than those associated with duplications, with a maximum tolerance in living organisms of 3 and $10 \%$ of the total genome, respectively (Brewer et al., 1998). Another study reported that patients with more distal deletions involving 13q33-13q34 do not show large structural malformations and growth deficiency (Schinzel, 1983). However, these patients are severely mentally handicapped. Therefore, it is most likely that the majority of the structural alterations manifested in our patient were caused by the partial $3 p$ trisomy, while the psychomotor alterations were caused by both syndromes. 
Table 1. Clinical manifestations related to $13 \mathrm{q}$ monosomy.

\begin{tabular}{ll}
\hline Segment deleted & Clinical manifestations \\
\hline 13q31.1-qter & $\begin{array}{l}\text { Profound intellectual deficiency, corpus callosum agenesis, Dandy-Walker malformation, cerebellar } \\
\text { hypoplasia, encephalocele, hypoplasia of optic nerve, microphthalmos, iris/choroid retina-coloboma, blindless, } \\
\text { hypotonia, hypertelorism, epicanthus, broad prominent nasal bridge, low-set ears, micrognathia, high and }\end{array}$ \\
& narrow palate, congenital heart defects, hand anomalies, foot anomalies, skeletal abnormalities (Ballarati et al., 2007) \\
& Discrete visceral atresia, holoprosencephaly, trigonocephaly (Brewer et al., 1998) \\
& Psychomotor retardation, hypotonia, short height, microcephaly, braquicephaly, facial asymmetry, short chin, \\
13q33 & ear abnormalities, hypospadia, hypertelorism, eyelid fissures, in-womb growth retardation, short neck, low-set \\
13q33 & Grs, lumbosacral myelomeningocele, anal prolapse (Brooks et al., 2006) \\
& Growth retardation, microcephaly, mental retardation, intrauterine growth retardation, hypertelorism, \\
& blepharophimosis, flat and broad nasal bridge, micrognathism, interatrial heart defect (Quélin et al., 2009) \\
& Growth retardation, intrauterine growth retardation, mental retardation, hypertelorism (Quélin et al., 2009) \\
13q33.3-qter & Oguchi’s disease, hypospadia, intellectual deficiency, cleft palate, factors VII and X deficiency (Schinzel, 1984) \\
13q34 & Moderate mental retardation, hypotonia, hypertelorism, foot anomalies, skeletal abnormalities (Ballarati et al., 2007) \\
13q34-qter &
\end{tabular}

Table 2. Clinical manifestations related to $3 p$ trisomy.

\begin{tabular}{ll}
\hline Segment duplicated & Clinical manifestations \\
\hline 3p21 & Holoprosencephaly, orofacial clefts, pyelectasis (Chen et al., 2008) \\
3p21.1 & $\begin{array}{l}\text { Dysmorphic facial features, hypertelorism, cleft lip and palate, large low-set ears, short neck, single transverse } \\
\text { palmar creases in both hands, hypochromic gray irides and pin point pupils, dysgenesis of the corpus callosum } \\
\text { (Han et al., 2012) }\end{array}$ \\
& $\begin{array}{l}\text { Death during the first 2 years of life, psychomotor retardation, braquicephaly, square-shaped face, hypertelorism, } \\
\text { micrognathia, short neck, congenital heart disease, frontal bossing, palate fissure, temporal depression, fingertip }\end{array}$ \\
whorls (Reiss et al., 1986) & $\begin{array}{l}\text { Cleft palate and hypotonia with gross motor and fine motor delay, speech delay, moderate atrial septal defect, } \\
\text { recurrent otitis media (Tan et al., 2011) }\end{array}$ \\
After-birth death, psychomotor retardation, frontal bossing, square-shaped face, hypertelorism, micrognathia, & congenital heart disease, temporal depression (Reiss et al., 1986) \\
3 p25 & $\begin{array}{l}\text { Microcephaly, bilateral microphthalmia, retinochoroidal coloboma, malformed and posteriorly rotated ears, } \\
\text { retrognathia, speech delay, "cupid's bow" superior lip, single palmar crease, flat feet, nail fragility, optic nerve } \\
\text { hypoplasia, delayed bone age (Ginocchio et al., 2008) }\end{array}$ \\
&
\end{tabular}

Finally, it should not be neglected that the father has a balanced translocation involving chromosomes 3 and 13, and even though he does not manifest any phenotypic abnormality, he has a higher probability of reproductive problems including miscarriages and descendants with chromosome abnormalities. The risk to carriers of balanced translocations has been shown to vary according to the chromosomal segments involved in the structural rearrangement. Therefore, genetic counseling for this family is highly recommended.

\section{Conflicts of interest}

The authors declare that they have no conflict of interest.

\section{ACKNOWLEDGMENTS}

Research supported by FAPEMA (Fundação de Amparo à Pesquisa e ao Desenvolvimento Científico e Tecnológico do Maranhão). We thank the patient's parents for their collaboration. 


\section{REFERENCES}

Ballarati L, Rossi E, Bonati MT, Gimelli S, et al. (2007). 13q Deletion and central nervous system anomalies: further insights from karyotype-phenotype analyses of 14 patients. J. Med. Genet. 44: e60.

Brewer C, Holloway S, Zawalnyski P, Schinzel A, et al. (1998). A chromosomal deletion map of humans malformations. Am. J. Hum. Genet. 63: 1153-1159.

Brooks BP, Meck JM, Haddad BR, Bendavid C, et al. (2006). Factor VII deficiency and developmental abnormalities in a patient with partial monosomy of $13 \mathrm{q}$ and trisomy of $16 \mathrm{p}$ : case report and review of the literature. BMC Med. Genet. 7: 2.

Chen CP, Wang TH, Lin CC, Tsai FJ, et al. (2008). Prenatal diagnosis of partial trisomy $3 \mathrm{p}$ (3p21 $\rightarrow$ pter) and partial monosomy $11 \mathrm{q}(11 \mathrm{q} 23 \rightarrow \mathrm{qter})$ associated with abnormal sonographic findings of holoprosencephaly, orofacial clefts, pyelectasis and a unilateral duplex renal system. J. Formos. Med. Assoc. 107: 822-826.

Ford CE and Hamerton JL (1956). The chromosomes of men. Nature 178: 1020-1023.

Ginocchio VM, De Brasi D, Genesio R, Ciccone R, et al. (2008). Sonic Hedgehog deletion and distal trisomy 3p in a patient with microphthalmia and microcephaly, lacking cerebral anomalies typical of holoprosencephaly. Eur. $J$. Med. Genet. 51: 658-665.

Han DH, Chang JY, Lee WI and Bae CW (2012). A case of partial trisomy 3p syndrome with rare clinical manifestations. Korean J. Pediatr. 55: 107-110.

Quélin C, Bendavid C, Dubourg C, de la Rochebrochard C, et al. (2009). Twelve new patients with 13q deletion syndrome: genotype-phenotype analyses in progress. Eur. J. Med. Genet. 52: 41-46.

Reiss JA, Sheffield LJ and Sutherland GR (1986). Partial trisomy 3p syndrome. Clin. Genet. 30: 50-58.

Schinzel A (1983). Catalogue of Unbalanced Chromosome Aberrations in Men. Walter De Gruyter Incorporated, Berlin.

Tan EC, Lim E, Cham B, Knight L, et al. (2011). Partial trisomy 3p and partial monosomy 11q associated with atrial septal defect, cleft palate, and developmental delay: a case report. Cytogenet. Genome Res. 134: 319-324.

Yunis JJ (1976). High resolution of human chromosomes. Science 191: 1268-1270. 